\title{
Domiciliary diurnal variation of exhaled nitric oxide fraction for asthma control
}

\author{
Junpei Saito, David Gibeon, Patricia Macedo, Andrew Menzies-Gow, \\ Pankaj K. Bhavsar and Kian Fan Chung
}

\section{Affiliations:}

Experimental Studies, National Heart and Lung Institute, Imperial College London and Biomedical Research Unit, Royal Brompton Hospital, London, UK.

\section{Correspondence:}

K.F. Chung, Airways Disease Section, National Heart and Lung Institute, Imperial College London, Dovehouse Street, London SW3 6LY, UK.

E-mail: f.chungQimperial.ac.uk

ABSTRACT A major goal of asthma management is maintaining optimal control. Current assessment is based on symptoms and lung function.

We evaluated whether domiciliary daily home exhaled nitric oxide fraction ( $F e N O)$ monitoring could be useful as an index of asthma control. 50 asthmatic subjects and 15 healthy volunteers with a range of asthma severity underwent asthma control questionnaire (ACQ), spirometry before and after salbutamol and sputum induction. FeNO and peak expiratory flow (PEF) were measured twice daily for 2 weeks. A record of exacerbations was obtained 3 months later.

Diurnal FeNO variation in uncontrolled asthmatics was significantly greater than in controlled asthmatics $(p<0.01)$. PEF variation was not different. The daily variation of FeNO levels was also greater in uncontrolled asthmatics compared with controlled asthmatic and healthy subjects $(\mathrm{p}<0.01)$. $80 \%$ of uncontrolled asthmatics experienced at least one or more exacerbations over the 3 months after the enrolment. The combination of diurnal FeNO variation $\geqslant 16.6 \%$ and ACQ scores $\geqslant 1.8$ was best at predicting uncontrolled asthma (area under curve $0.91,95 \%$ CI $0.86-0.97 ; \mathrm{p}<0.001$ ).

Diurnal variation in FeNO can be used as a biomarker of asthma control and as a predictor of the risk of future exacerbation. Prospective studies are warranted.

@ERSpublications

Diurnal variation in FeNO can be used as a biomarker of asthma control and a predictor of the risk of future exacerbation http://ow.ly/r2MCY

Received: March 182013 | Accepted after revision: July 302013 | First published online: Aug 152013

Support statement: This project was supported by the National Institute for Health Research (NIHR) Respiratory Disease Biomedical Research Unit at the Royal Brompton NHS Foundation Trust and Imperial College London (both London, UK). K.F. Chung is a senior investigator of NIHR. J. Saito was supported by a grant from the Fukushima Medical University, Fukushima, Japan.

Conflict of interest: Disclosures can be found alongside the online version of this article at www.erj.ersjournals.com

Copyright @ERS 2014 


\section{Introduction}

Over the past decade, there has been a clearer definition of the concepts of asthma severity and control with important implications for the management of asthma. Asthma control is defined by the components of clinical control and future risk of exacerbation, and asthma severity by the requirement for high intensity treatment [1]. The Global Initiative for Asthma (GINA) has also emphasised that a major goal of asthma management is not only achieving and maintaining optimal control but also reducing future risks, particularly those of exacerbations [2]. Symptom questionnaires and spirometry have been recommended for managing asthma [2]. The guidelines have also recommended the need for assessing control over a period of time rather than just at one assessment. Hence, home monitoring can be important for this $[3,4]$. Daily home monitoring of peak expiratory flow (PEF) also provides an additional tool for asthma management $[5,6]$.

Using the recommended criteria for determining control, between $20 \%$ and $50 \%$ of asthma patients have been reported to be uncontrolled [7-9]. Uncontrolled asthma is associated with a decreased quality of life, chronic airflow limitation, a higher risk of having an exacerbation and hospitalisation, associated with a greater probability of death, and an increased economic burden [10-13]. One of the potential reasons for a continuing poor level of control is that the tools currently available to evaluate control may not be adequate. For example, a marker of inflammation is not currently included in the assessment of control when the level of airway inflammation is generally accepted to contribute to symptoms and to the risk of exacerbations [2].

Measurement of exhaled nitric oxide fraction ( $\mathrm{FeNO}$ ) has been available as an indirect way of assessing the eosinophilic inflammation of asthma [14]. Longitudinal measurements of FeNO in asthmatics may be helpful to predict deterioration $[15,16]$. These daily fluctuations have been proposed to inform about both severity and control of asthma [17]. With the arrival of portable FeNO monitors, it is now possible for patients to measure FeNO in the home environment on a daily basis $[17,18]$.

We evaluated whether domiciliary diurnal variations and fluctuations of FeNO levels provide useful information to assess asthma control and determined their value for predicting future risks, particularly of asthma exacerbations. In addition, we wanted to determine whether these also could provide information about asthma severity. Finally, we determined how comparable this was to the analysis of PEF diurnal measurements.

\section{Methods}

\section{Subjects}

50 asthmatic subjects ( 22 nonsevere and 28 severe asthmatics) were recruited from outpatient clinics at the Royal Brompton Hospital, London, UK, and 15 normal healthy volunteers through advertisements. The diagnosis of asthma was made by respiratory physicians according to a clinical history of characteristic symptoms (i.e. dry cough, wheezing, chest tightness and breathlessness), as well as a history of either forced expiratory volume in $1 \mathrm{~s}(\mathrm{FEV} 1)$ reversibility $\geqslant 12 \%$ or provocative concentration of methacholine causing a $20 \%$ fall in FEV1 (PC20) of $<8 \mathrm{mg} \cdot \mathrm{mL}^{-1}$. Asthmatic subjects were categorised as having controlled, partly controlled or uncontrolled asthma according to GINA guidelines [2].

Uncontrolled asthmatic subjects were defined as having three or more features of the following features over 4 weeks before recruitment: 1 ) daily symptoms more than twice a week; 2) any limitation of activities; 3 ) any nocturnal symptoms or awakening; 4) need for reliever/rescue treatment more than twice a week; and 5) spirometry (PEF or FEV1) $<80 \%$ predicted or personal best if known [2]. Patients who had fewer than two of these features were assigned as having stable controlled asthma, which includes controlled and partly controlled asthma. Asthma subjects were also defined as having severe asthma according to the American Thoracic Society (ATS) definition of severe therapy-resistant asthma [19].

Subjects were excluded if they were current smokers, had other concomitant respiratory diseases other than asthma, or a respiratory tract infection within 6 weeks of study entry. Healthy volunteers were defined as having a smoking history of $<5$ pack-years, no respiratory diseases and a negative PC20 $\left(>16 \mathrm{mg} \cdot \mathrm{mL}^{-1}\right)$.

All participants gave informed consent to the protocol approved by the Ethics Committee of Royal Brompton and Harefield NHS Trust/National Heart and Lung Institute, London, UK.

\section{Study design}

At study entry, all subjects performed spirometry before and after four puffs of $\beta_{2}$-adrenergic agonist (salbutamol), sputum induction, asthma control questionnaire (ACQ) [20], asthma quality life questionnaire (AQLQ) [21] and asthma severity, as well as asthma control status in line with the GINA guidelines [2]. Next, a portable FeNO monitor (NObreath; Bedfont Scientific Ltd, Rochester, UK), a peak flow monitor (PIKO; nSpire Health Ltd, London, UK) and an asthma diary were provided to all subjects in 
order to measure FeNO and PEF levels twice a day over 2 weeks at home. At the second visit, when subjects brought the monitors back, the asthma diary was collected.

\section{Spirometry and reversibility tests}

Spirometry tests were performed with a dry wedge spirometer (Vitalograph, Buckingham, UK) on the first visit. Asthmatic subjects continued their usual medications except for salbutamol. Forced vital capacity (FVC) and FEV1 levels before and after inhalation of $400 \mu \mathrm{g}$ salbutamol were recorded and the best of three acceptable manoeuvres reproducible to within $200 \mathrm{~mL}$ or $5 \%$ was retained [22].

\section{FeNO and PEF measurements}

At the first visit, all subjects were instructed on how to obtain measurements of FeNO and PEF, and to follow these measurements while taking their inhaled therapy. FeNO measurements were conducted at a constant flow of $50 \mathrm{~mL} \cdot \mathrm{s}^{-1}$ in line with the ATS/European Respiratory Society (ERS) recommendations using a portable handheld analyser (Nobreath; Bedfont Scientific Ltd) [23]. FeNO was performed twice a day for 2 weeks. Three successive measurements were performed on each occasion and levels were recorded in the diary. PEF measurements were also made three times after FeNO assessment. The best of the three readings was automatically recorded onto the monitor. All measurements over 2 weeks were transferred to a computer when subjects returned the monitor.

In order to avoid measurement bias, subjects were asked to measure FeNO and PEF at the same time and the same place twice a day, in the morning between 07:00 $\mathrm{h}$ and 10:00 h, and in the evening between 18:00 $\mathrm{h}$ and 21:00 h. Subjects were advised not to take their usual medications prior to making the FeNO or PEF measurements. FeNO was measured prior to PEF measurements.

\section{Recording of asthma exacerbations}

After the 2 weeks of measurements, patients were asked to keep a record of exacerbations over the subsequent 3 months, and were reviewed at 3 months. Severe exacerbations were defined as those needing treatment with oral prednisolone, or an increase in the maintenance dose of prednisolone for at least $\geqslant 3$ days, or a hospitalisation or emergency room visit because of asthma, requiring systemic corticosteroids. Moderate exacerbations were defined as $\geqslant 2$ days with having one or more of the following: deterioration in symptoms, deterioration in PEF levels and increased rescue bronchodilator use that is not severe enough to warrant systemic corticosteroid use [5].

\section{Data analysis}

Data are shown as mean (95\% confidence interval). The daily morning and evening FeNO levels were calculated as the mean of two or three measurements. Diurnal variations of FeNO and PEF were expressed as the amplitude (highest-lowest). In addition, we used other ways of expressing the daily variation of these parameters in relation to their predictive value for uncontrolled asthma (table 1). The diurnal variations of FeNO and PEF were compared between groups using Kruskall-Wallis and Mann-Whitney U-test with Bonferroni correction. Receiver operating characteristic (ROC) curves were constructed and the area under

TABLE 1 Exhaled nitric oxide fraction ( $F$ eNO) and peak expiratory flow (PEF) expressed in different ways in relation to their predictive values for uncontrolled asthma

\section{Predictors}

Formula

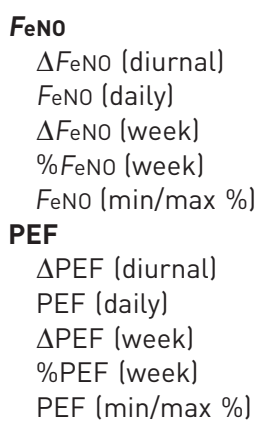

\author{
FeNO (highest in a day - lowest in a day) \\ FeNO (morning + evening)/2 \\ FeNO (highest over 2 weeks - lowest over 2 weeks) \\ FeNO (highest over 2 weeks - lowest over 2 weeks)/2 weeks mean \\ FeNO (lowest over 2 weeks/highest over 2 weeks) $\times 100$ \\ PEF (highest in a day - lowest in a day) \\ PEF (morning + evening)/2 \\ PEF (highest over 2 weeks - lowest over 2 weeks) \\ PEF (highest over 2 weeks - lowest over 2 weeks)/2 weeks mean \\ PEF (lowest over 2 weeks/highest over 2 weeks) $\times 100$
}

$\Delta \mathrm{FeNO}_{\mathrm{e}}$ change in FeNO; min/max \%: minimum as a percentage of maximum; $\triangle \mathrm{PEF}$ : change in PEF. 
Stable controlled asthma

Healthy nonasthma

15
$36.2(30.8-41.6)$
$10 / 5$
$168(164-173)$
$63.9(54.5-73.2)$
$22.3(19.9-24.7)$
0
0
NA
$100(93.9-107)$
$83.7(80.5-87.0)$
$0.59(0.20-0.98)$
$34.5(22.2-46.9)$
NA
NA
NA
NA
NA
NA
NA
NA
NA
NA

$42.3(35.6-49.0)$

$8 / 14$

169 (165-173)

$72.2(65.3-79.2)$

$25.3(23.2-27.4)$

$63.6^{*}$

$54.5^{*}$

$15 / 7$

$79.7(73.4-86.1)^{*}$

$72.0(69.0-75.0)^{*}$

$4.79(1.82-7.76)^{*}$

$55.9(41.8-69.9)$

$1.41(1.04-1.78)$

$5.78(5.40-6.16)$

\section{AQLQ \\ Medication taken}

Inhaled corticosteroid

Long-acting $\beta_{2}$-agonist

Leukotriene antagonist

Theophylline

Oral prednisolone

Omalizumab

As-needed reliever use inhalations

of SABA per day

ICS (BDP equivalent) $\mu \mathrm{g}$
$16(72.7)$

$15(68.2)$

$6(27.3)$

$1(4.54)$

$4(18.2)$

$1(4.54)$

$0.49(0.07-1.06)$

1009 (620-1398)
Uncontrolled asthma

$$
\begin{gathered}
28 \\
51.4(46.1-56.6)^{*} \\
10 / 18 \\
168(164-171) \\
77.9(70.4-85.4)^{*} \\
27.8(25.2-30.3) \\
85.7^{*} \\
64.3^{*} \\
7 / 21 \\
66.8(58.0-75.5)^{*, \#} \\
67.9(62.6-73.2)^{*} \\
18.5(2.91-34.0)^{*}, \# \\
39.0(21.1-56.8) \\
2.52(2.05-2.98)^{\#} \\
4.49(4.00-4.99)^{\#} \\
\\
27(96.4)^{\#} \\
25(89.3)^{\#} \\
7(25.0) \\
11(39.3)^{\#} \\
14(50.0)^{\#} \\
2(7.1) \\
3.59(2.34-4.84)^{\#} \\
1804(1543-2065)^{\#}
\end{gathered}
$$

Data are presented as mean (95\% confidence interval) or $n$ (\%), unless otherwise stated. BMI: body mass index; FEV1: forced expiratory volume in $1 \mathrm{~s} ; \%$ pred: \% predicted; FVC: forced vital capacity; ACQ: asthma control questionnaire; AQLQ: asthma quality of life questionnaire; SABA: shortacting $\beta 2$-agonist; ICS: inhaled corticosteroid; BDP: beclomethasone dipropionate; NA: not applicable. ${ }^{*}: p<0.05$ versus healthy; ${ }^{\#}$ : $<0.05$ versus stable controlled asthmatic subjects.

the curves (AUCs) were determined for the detection of uncontrolled asthma. Multivariate logistic regression analysis was performed to these three markers simultaneously in order to determine the independent predictors of uncontrolled asthma. Finally, the Chi-squared test was used to evaluate the exacerbation rates between stable controlled and uncontrolled asthmatic subjects. A two-tailed p-value of $<0.05$ was considered significant.

\section{Results}

Characteristics of subjects

22 subjects had stable controlled asthma and 28 had uncontrolled asthma (table 2). Sputum eosinophils (\%) in both stable and uncontrolled asthmatic groups were significantly higher compared to those in the healthy group $(\mathrm{p}<0.05)$. There was a significant positive correlation between FeNO levels at the study entry and reversibility to salbutamol $(r=0.663, p<0.001)$ and sputum eosinophil $\%(r=0.370, p=0.014)$. There was a negative correlation between FeNO levels at entry, FEV1 \% pred $(\mathrm{r}=-0.393, \mathrm{p}=0.001)$ and PEF \% pred $(\mathrm{r}=-0.379, \mathrm{p}=0.002)$. There was no difference in the incidence of allergic rhinitis between stable controlled and uncontrolled asthmatic subjects.

\section{Diurnal variation FeNO and PEF}

Examples of individual diurnal variation in FeNO and PEF are shown in figure 1. There was a significant diurnal $F$ eNO variation $(\Delta F \mathrm{eNO}$ (diurnal)) in uncontrolled asthmatic subjects (mean $15.6 \mathrm{ppb}$, 95\% CI 12.5-18.7 ppb) compared with stable controlled asthmatics (mean $8.18 \mathrm{ppb}$, 95\% CI 6.69$9.67 \mathrm{ppb}$ ) and healthy subjects (mean $6.05 \mathrm{ppb}, 95 \%$ CI $5.19-6.90 \mathrm{ppb})(\mathrm{p}<0.001)$. Conversely, no significant diurnal variation in PEF levels $(\triangle \mathrm{PEF}$ (diurnal)) was observed in uncontrolled and stable controlled asthmatic subjects (mean $39.4 \mathrm{~L} \cdot \mathrm{min}^{-1}$, 95\% CI $30.3-48.5 \mathrm{~L} \cdot \mathrm{min}^{-1}$ versus mean $34.5 \mathrm{~L} \cdot \mathrm{min}^{-1}$, 95\% CI 29.1-39.9 L. $\mathrm{min}^{-1}$ ) (fig. $2 \mathrm{a}$ and b). When the asthmatic groups were divided according to asthma severity, no significant differences in $\triangle F$ eNO (diurnal) and $\triangle \mathrm{PEF}$ (diurnal) could be found between nonsevere and severe groups, but there was a greater variation in these parameters between asthmatic 

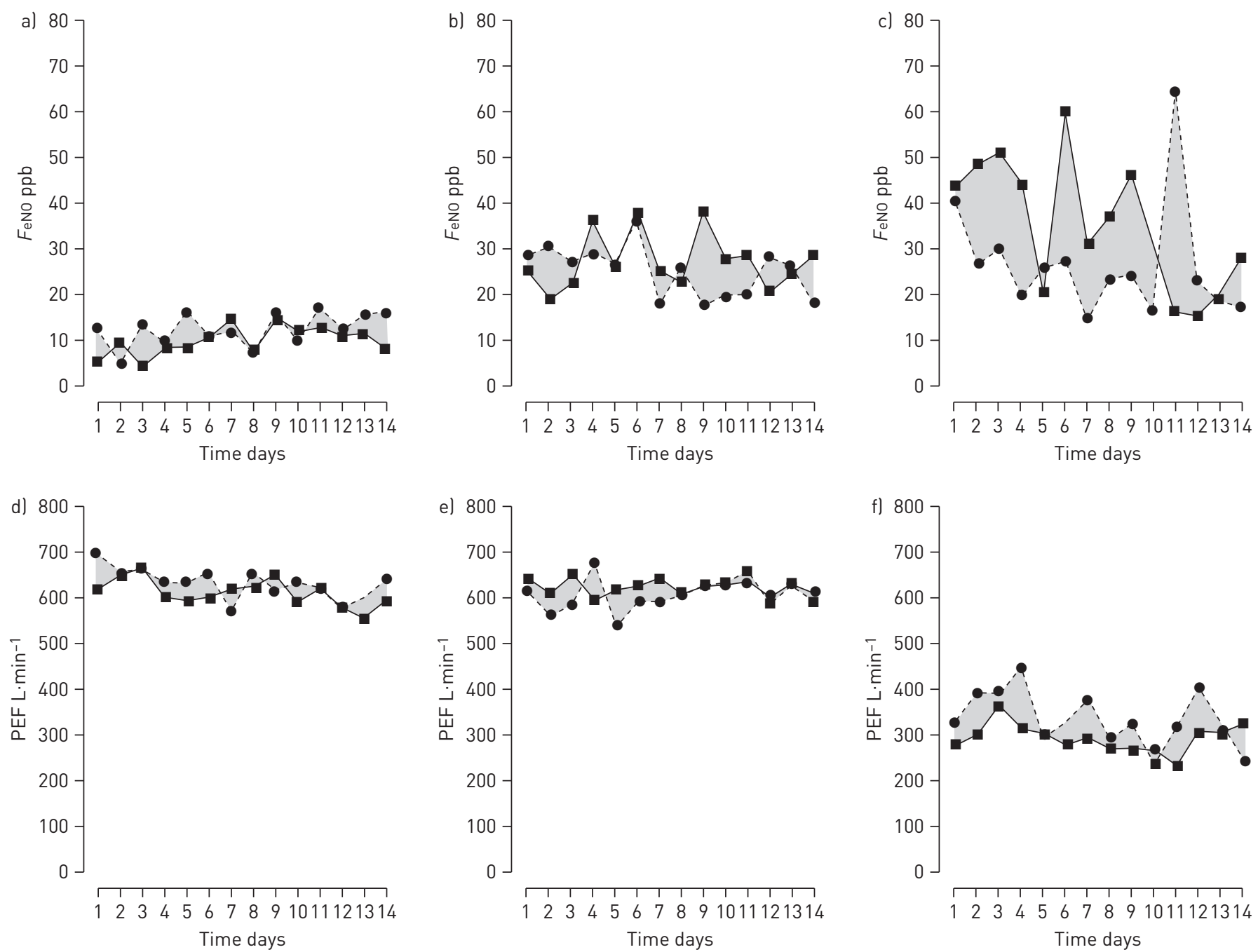

FIGURE 1 Examples of typical individual patterns of exhaled nitric oxide fraction ( $F \mathrm{eNO}$ ) and peak expiratory flow (PEF) levels over 2 weeks in a and d) healthy, $\mathrm{b}$ and e) stable controlled and $\mathrm{c}$ and f) uncontrolled asthmatic subjects. Morning FeNO and PEF levels are connected with solid lines, and evening FeNO and PEF levels with dotted lines.

groups and healthy subjects (fig. $2 \mathrm{c}$ and d). In addition, being on asthma medications such as oral prednisolone or theophylline did not influence the diurnal variation of FeNO levels.

Fluctuations of daily average FeNO and PEF levels over 2 weeks

The daily average FeNO levels in uncontrolled asthmatic subjects over 2 weeks were significantly higher than those in stable controlled asthmatic subjects (mean 48.6 ppb, 95\% CI 38.9-58.4 ppb versus mean 34.5 ppb, 95\% CI 27.6-41.4 ppb; $\mathrm{p}=0.03$ ) and healthy subjects (mean $48.6 \mathrm{ppb}$, 95\% CI 38.9-58.4 ppb versus mean $18.1 \mathrm{ppb}, 95 \%$ CI $14.6-21.7 \mathrm{ppb} ; \mathrm{p}<0.001$ ). In addition, the fluctuation pattern in uncontrolled asthmatic subjects was significantly different from those in stable controlled asthmatics and healthy subjects according to repeated ANOVA analysis $(\mathrm{p}<0.001$ ) (fig. $3 \mathrm{a}$ ), whereas the fluctuation pattern between stable controlled and healthy subjects showed no difference. When asthmatic subjects were divided into asthma severities, there was no significant difference in the daily average FeNO levels as well as the fluctuation pattern between nonsevere and severe asthmatic group (fig. 3b).There was no significant difference in the fluctuation pattern of FeNO levels between morning and evening (data not shown).

Figure $4 \mathrm{a}$ shows the daily average levels of PEF based on asthma control status. The daily average PEF levels in uncontrolled asthmatic subjects were significantly lower than those in stable controlled asthmatic subjects (mean $311 \mathrm{~L} \cdot \mathrm{min}^{-1}$, 95\% CI $277-346 \mathrm{~L} \cdot \mathrm{min}^{-1}$ versus mean $415 \mathrm{~L} \cdot \mathrm{min}^{-1}$, 95\% CI 377-452 L $\cdot \mathrm{min}^{-1}$; $\mathrm{p}<0.001$ ) and healthy subjects (mean $311 \mathrm{~L} \cdot \mathrm{min}^{-1}, 95 \%$ CI $277-346 \mathrm{~L} \cdot \mathrm{min}^{-1}$ versus mean $513 \mathrm{~L} \cdot \mathrm{min}^{-1}, 95 \%$ CI $\left.482-544 \mathrm{~L} \cdot \mathrm{min}^{-1} ; \mathrm{p}<0.001\right)$. In addition, there were no significant fluctuated patterns in the daily 
average PEF levels over 2 weeks between healthy, stable controlled and uncontrolled asthmatic subjects $(\mathrm{p}>0.05)$. Similar results could be obtained when subjects were divided into healthy, nonsevere asthmatic and severe asthmatic subjects (fig. 4b). There was no difference in the fluctuation pattern of PEF levels between morning and evening (data not shown).

\section{Asthma exacerbations}

In uncontrolled asthmatic subjects group, 22 (78.6\%) subjects experienced at least one or more asthma exacerbations, while only two (9\%) subjects in stable controlled asthmatic subjects group suffered from exacerbation over the next 3 months after completed measurements $(\mathrm{p}<0.001)$ (table 3$) .16(57.1 \%)$ out of 24 asthmatic subjects with exacerbation had severe and eight (36.3\%) had nonsevere asthma (table 4 ).

\section{FeNO and PEF as predictor of control}

ROC curves were constructed for predicting uncontrolled asthma using different patterns of calculations in FeNO and PEF levels (table 5). In terms of FeNO levels, $\Delta F$ eNO (diurnal) was the best predictor for evaluating uncontrolled asthmatic subjects (AUC 0.803 , sensitivity of $64.3 \%$, specificity of $95.5 \%$, positive predictive value (PPV) of $94.7 \%$ and negative predictive value (NPV) of $67.7 \% ; \mathrm{p}<0.001$ ). With regard to PEF levels, the best parameter to estimate uncontrolled asthmatic subjects was minimum PEF expressed as a percentage of maximum PEF (AUC 0.741 , sensitivity of $60.7 \%$, specificity of $81.8 \%$, PPV of $81.0 \%$ and NPV of $62.1 \%$; $\mathrm{p}<0.001$ ) and \%PEF (week) (AUC 0.741 , sensitivity of $60.7 \%$, specificity of $81.8 \%$, PPV of $81.0 \%$ and NPV
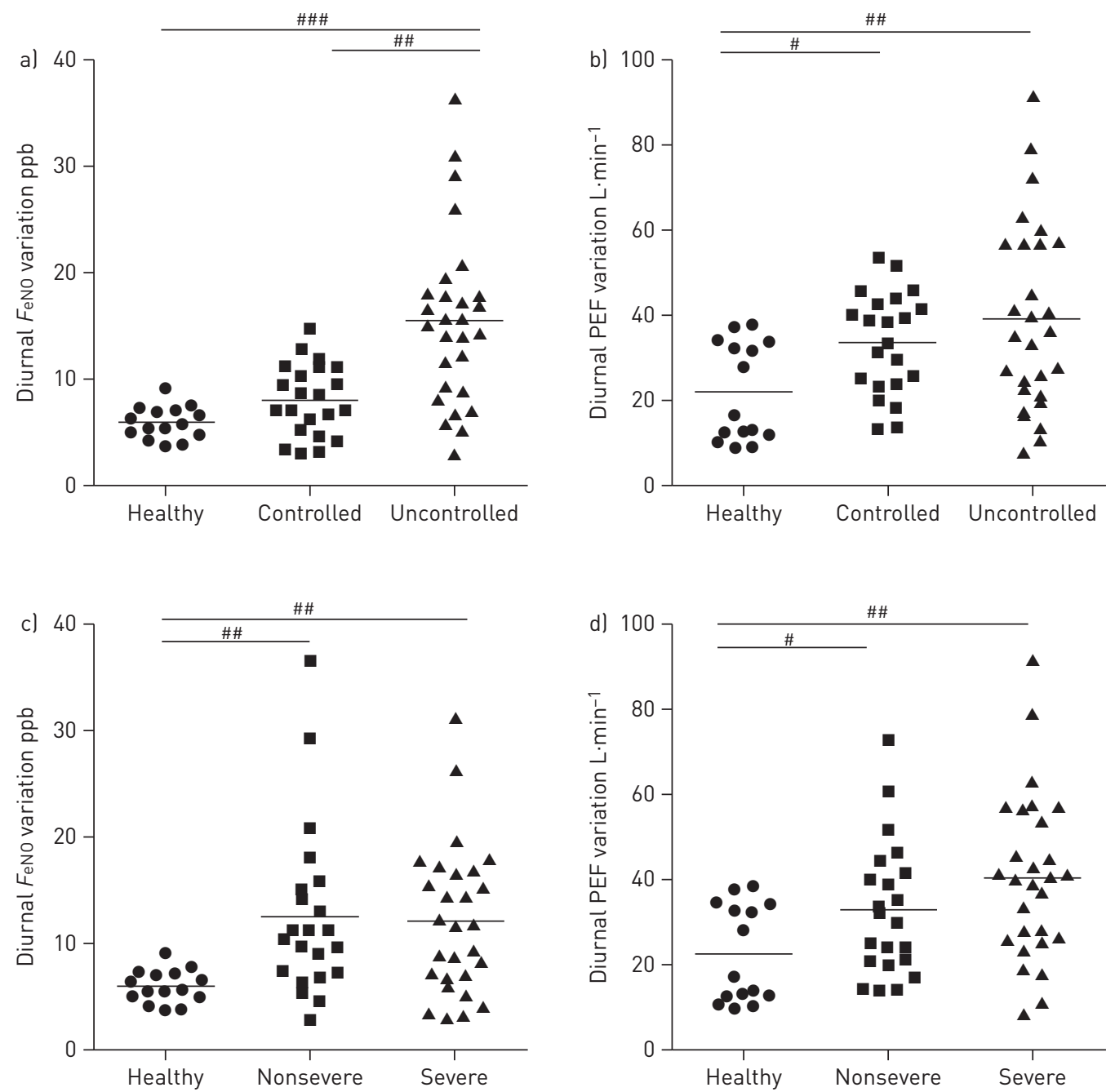

FIGURE 2 Diurnal variations of a and c) exhaled nitric oxide fraction (FeNO) and b and d) peak expiratory flow (PEF) levels in healthy and asthmatic subjects according to either asthma severity or asthma control are shown. \#: $\mathrm{p} \leqslant 0.05$;

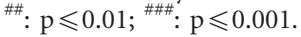



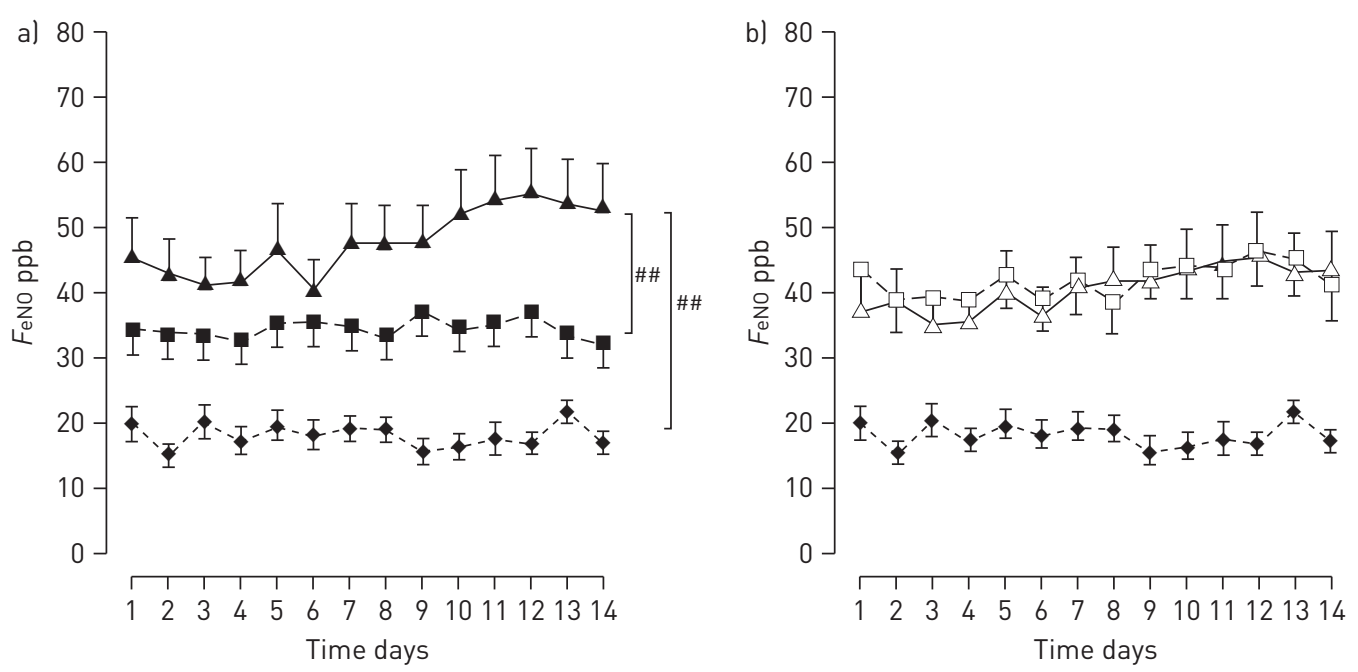

FIGURE 3 Daily mean variation of exhaled nitric oxide fraction ( $F e N O)$ levels over 2 weeks according to a) asthma control status or b) asthma severity. Uncontrolled asthmatics (solid triangles), stable controlled asthmatics (solid squares), severe asthmatics (open triangles), nonsevere asthmatics (open squares) and healthy subjects (solid diamonds) are shown. Data are expressed mean \pm SE. ${ }^{\# \#}: \mathrm{p} \leqslant 0.01$ versus stable controlled asthmatic subjects and healthy subjects.

of $62.1 \%$; $\mathrm{p}<0.001$ ). ACQ score (AUC 0.772 , sensitivity of $71.4 \%$, specificity of $86.4 \%$, PPV of $87.0 \%$ and NPV of $70.4 \% ; \mathrm{p}<0.001)$ was noted to predict uncontrolled asthmatic subjects.

Multiple logistic regression and ROC curves for predicting control

According to the multiple logistic regression analysis, ACQ scores, $\triangle F$ eNO (diurnal) and minimum PEF expressed as a percentage of maximum PEF were found to be independent parameters for predicting uncontrolled asthmatic subjects (table 6). Neither marker was superior according to the AUC curves, but the combination of $\Delta F$ eNO (diurnal) $\geqslant 16.6 \%$ and ACQ scores $\geqslant 1.8$ was the best marker to detect uncontrolled asthmatic subjects with sensitivity of $85.7 \%$, specificity of $86.4 \%$, PPV of $88.9 \%$ and NPV of 82.6\% (AUC 0.914, 95\% CI 0.857-0.971; p<0.001) (figure 5).

\section{Discussion}

In 50 patients with asthma subdivided according to asthma control, we found significant diurnal FeNO variations in uncontrolled asthmatic subjects compared with stable controlled asthmatic and healthy
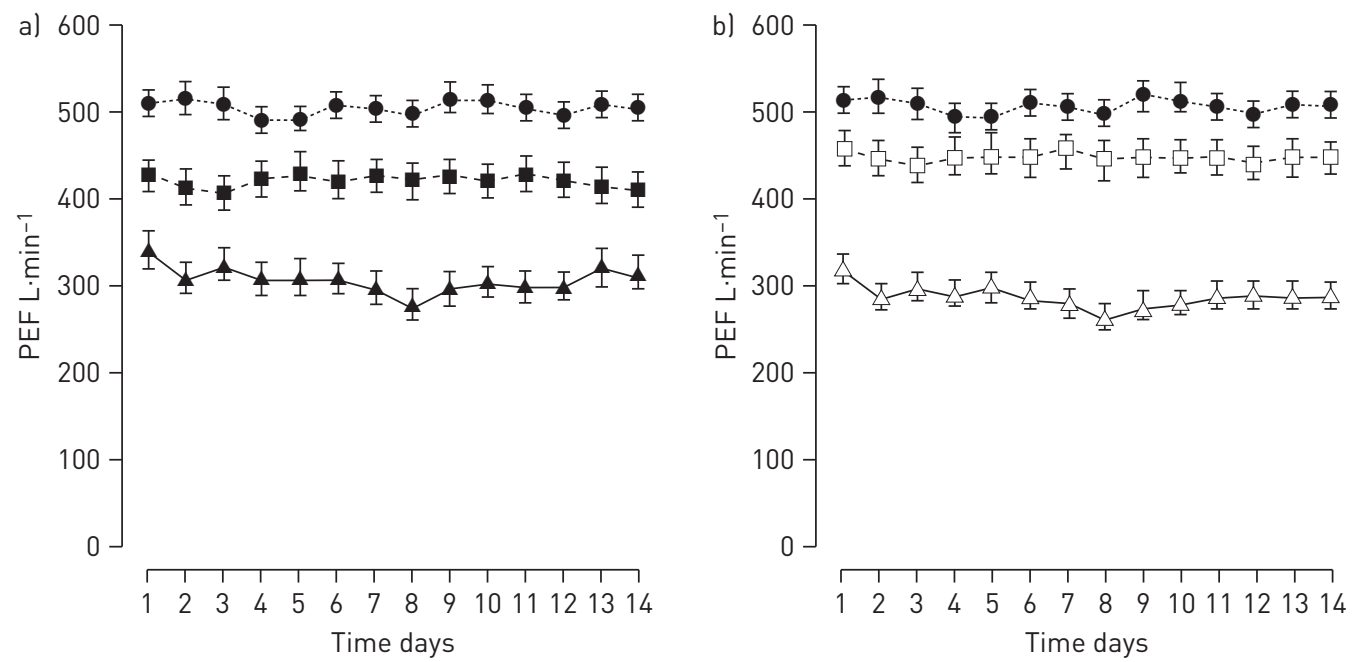

FIGURE 4 Daily average variation of peak expiratory flow (PEF) levels over 2 weeks according to a) asthma control status or b) asthma severity. Uncontrolled asthmatics (solid triangles), stable controlled asthmatics (solid square), severe asthmatics (open triangles), nonsevere asthmatics (open square) and healthy subjects (solid circles) are shown. Data are expressed mean $\pm \mathrm{SE}$. 
TABLE 3 Asthma control and exacerbations over 3 months follow-up

Stable controlled asthmatic subjects

Uncontrolled asthmatic subjects

Total

\begin{tabular}{lccc}
\hline Severe exacerbation & $2(9)$ & $12(42.9)$ & 14 \\
Moderate exacerbation & $0(0)$ & $10(35.7)$ & $6(21.4)$ \\
No exacerbation & $20(91)$ & $28(100)$ & 26 \\
Total & $22(100)$ & 50 & \\
\hline
\end{tabular}

Data are presented as $\mathrm{n}(\%)$ or $\mathrm{n}$. Chi-squared test: $\mathrm{p}<0.001$.

TABLE 4 Asthma severity and exacerbations over 3 months follow-up

Nonsevere asthmatic subjects

Severe asthmatic subjects

Total

\begin{tabular}{|c|c|c|c|}
\hline Severe exacerbation & $3(13.6)$ & $11(39.2)$ & 14 \\
\hline Moderate exacerbation & $5(22.7)$ & $5(17.9)$ & 10 \\
\hline No exacerbation & $14(63.6)$ & 12 (42.9) & 26 \\
\hline Total & $22(100)$ & $28(100)$ & 50 \\
\hline
\end{tabular}

Data are presented as $\mathrm{n}(\%)$ or $\mathrm{n}$. Chi-squared test: $\mathrm{p}=$ nonsignificant.

subjects. In addition, the daily average FeNO levels, but not PEF, in uncontrolled asthmatic subjects over 2 weeks showed a greater fluctuation than those in stable controlled asthmatic and healthy subjects. Severity of asthma was indicated by the raised level of baseline FeNO but not by the disturbance in diurnal variation. Finally, the combination of diurnal FeNO variation and ACQ scores, rather than the use of each parameter separately, provides better information to predict uncontrolled asthma and future risks of asthma exacerbation.

FeNO has been shown to mirror eosinophilic inflammation in the airways of patients with asthma [14]. Studies have also supported its role in reflecting asthma control $[15,24,25]$ and as a marker of response to inhaled corticosteroid therapy $[26,27]$. However, several studies have shown its limitation in monitoring asthma therapy [28-30]. Support for a greater usefulness of daily FeNO measurements has recently been

TABLE 5 Diagnostic value of different parameters or combination of markers for predicting uncontrolled asthma

\begin{tabular}{|c|c|c|c|c|c|c|}
\hline Predictors & AUC & Sensitivity \% & Specificity \% & PPV \% & NPV \% & p-value \\
\hline \multicolumn{7}{|l|}{ FeNO } \\
\hline$\Delta F_{\mathrm{eNO}}$ (diurnal) & $0.803(0.715-0.891)$ & 64.3 & 95.5 & 94.7 & 67.7 & $<0.001$ \\
\hline$\Delta F_{e N O}$ (week) & $0.789(0.699-0.878)$ & 67.9 & 86.4 & 86.4 & 67.9 & $<0.001$ \\
\hline$\%$ FeNo (week) & $0.721(0.619-0.824)$ & 85.7 & 54.5 & 70.6 & 75.0 & $<0.001$ \\
\hline FeNo $(\min / \max \%)$ & $0.720(0.615-0.825)$ & 82.1 & 63.6 & 74.2 & 73.7 & $<0.001$ \\
\hline \multicolumn{7}{|l|}{ PEF } \\
\hline PEF (daily) & $0.735(0.637-0.833)$ & 57.1 & 77.3 & 76.2 & 58.6 & $<0.001$ \\
\hline$\triangle P E F$ (week) & $0.619(0.505-0.733)$ & 53.6 & 81.8 & 78.9 & 58.1 & 0.048 \\
\hline \%PEF (week) & $0.741(0.641-0.840)$ & 60.7 & 81.8 & 81.0 & 62.1 & $<0.001$ \\
\hline $\mathrm{PEF}(\min / \max \%)$ & $0.741(0.641-0.840)$ & 60.7 & 81.8 & 81.0 & 62.1 & $<0.001$ \\
\hline ACQ score & $0.772(0.677-0.867)$ & 71.4 & 86.4 & 87.0 & 70.4 & $<0.001$ \\
\hline \multicolumn{7}{|l|}{ Combination } \\
\hline
\end{tabular}

Data are presented as mean (95\% confidence interval), unless otherwise stated. AUC: area under the curve; PPV: positive predictive value; NPV: negative predictive value; FeNO: exhaled nitric oxide fraction; $\Delta F_{e N O}$ : change in $F e N O ; m i n / m a x \%$ : minimum as a percentage of maximum; PEF: peak expiratory flow; $\triangle \mathrm{PEF}$ : change in $\mathrm{PEF} ; \mathrm{ACQ}$ : asthma control questionnaire. 
TABLE 6 Predictors for discriminating uncontrolled asthma from stable controlled asthma using multiple logistic regression analysis

\begin{tabular}{lcc} 
Predictors & OR $(95 \%$ Cl) & p-value \\
\hline ACQ scores & $3.31(1.23-8.90)$ & 0.018 \\
$\Delta$ FeNO (diurnal) & $1.39(1.17-1.65)$ & $<0.001$ \\
PEF (min/max \%) & $0.94(0.89-0.99)$ & 0.015 \\
FEV $1 \%$ predicted & $0.99(0.94-1.04)$ & 0.62 \\
\hline
\end{tabular}

ACQ: asthma control questionnaire; FeNO: exhaled nitric oxide fraction; $\triangle F$ eNO: change in FeNO; PEF: peak expiratory flow; $\min / \max \%$ : minimum as a percentage of maximum; FEV1: forced expiratory volume in $1 \mathrm{~s}$.

obtained $[17,18,31,32]$. In the current study, a single measurement of FeNO correlated well with FEV1 \% pred and with percentage of sputum eosinophils, indicating that FeNO reflected both the inflammatory component as well as airflow obstruction. A recent study showed that the level of asthma control was associated with inflammatory markers including FeNO and airway mucosal eosinophil numbers [33]. Our new findings indicate that the daily fluctuation and the diurnal variation of FeNO provided more information regarding the control of asthma and the future risk of exacerbation. Our data is in agreement with recent studies reporting that monitoring of FeNO revealed changes in FeNO prior to the onset of moderate exacerbations [32], and that analysis of the fluctuation of daily FeNO provided useful information on asthma control [17].

In our study, $\triangle F \mathrm{FO}$ (diurnal), but not $\triangle \mathrm{PEF}$ (diurnal), in uncontrolled asthmatic subjects was significantly higher than in stable controlled asthma. There are reports indicating good relationships between diurnal PEF variations, asthma control and asthma exacerbation $[6,34,35]$, while others report only limited usefulness as a measure of asthma control [36-38]. However, there are reports of significant diurnal variation in FeNO measurements in the mornings compared with evenings, as we have found [18, 39]. In our study, we measured the fluctuation as the absolute variability irrespective of whether the level was higher or lower in any one direction. Frey and colleagues reported that the exponent of long-range fluctuation $(\alpha$ value) of FeNO and PEF predicted individual future risks of asthma exacerbation and reflected the current state of asthma control $[6,17,35,40]$. Our short-term analysis over only 2 weeks indicated that the diurnal fluctuation in FeNO was more related to asthma control than PEF was. $\Delta F$ eNO (diurnal) appears to be a better marker than $F$ eNO (daily), $\Delta F$ eNO (week) or $\% F e N O$ (week) for predicting asthma control and future risks of asthma exacerbation.

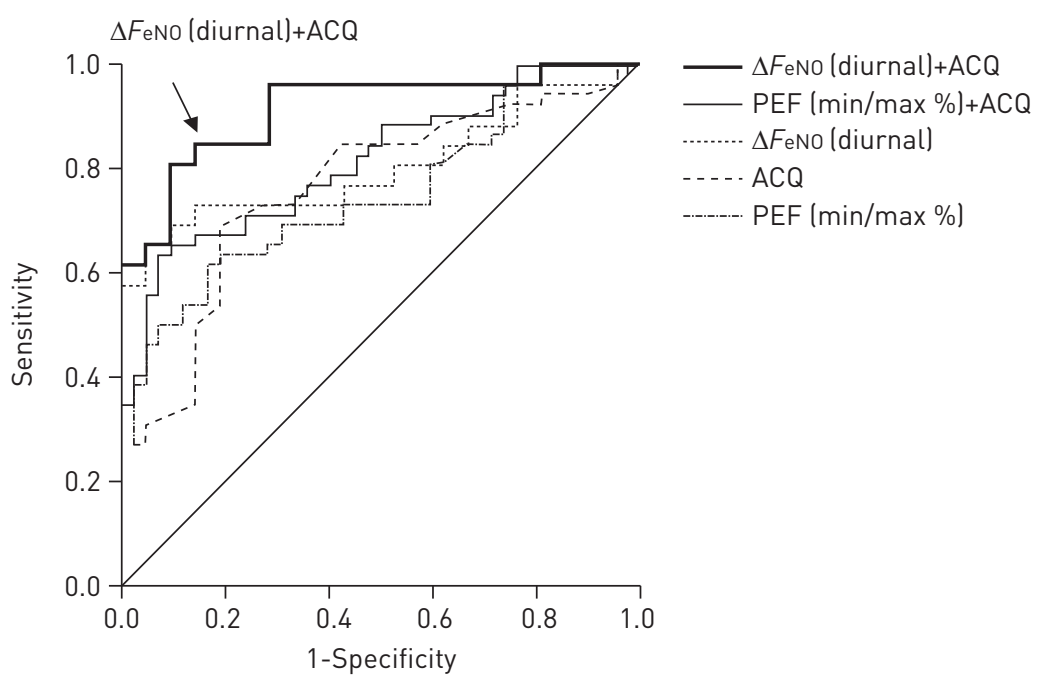

FIGURE 5 Combined receiver operator characteristics curve for daily exhaled nitric oxide fraction ( FeNO) variation, peak expiratory flow (PEF) ratio (minimum as a percentage of maximum $(\min / \max \%)$ ) and asthma control questionnaire (ACQ) score. The combination of daily FeNO variation and ACQ score was the best parameter to differentiate uncontrolled asthmatic subjects from stable controlled asthmatic subjects $(\mathrm{p}<0.001) . \Delta F_{\text {eNO}}$ : change in FeNO. 
When $\triangle F$ eNO (diurnal) and ACQ scores are combined, the highest AUC could be obtained, whereas neither parameter seemed superior when used alone. In addition, these parameters are independent of each other from the multiple logistic regression analysis. There is no gold standard to estimate asthma control. What is clear is that no single parameter is adequate to assess asthma control and to predict future risks of exacerbation $[5,41]$. However, our results showed that most uncontrolled asthmatic subjects experienced asthma exacerbation over the following 3 months after measurements had been made, suggesting that asthma control could strongly influence the future risk of exacerbation, as reported previously [10-12].

One potential limitation of the study is that we did not assess adherence to treatment and because FeNO has been previously used to assess patient adherence [42], our diurnal variation of FeNO may be a reflection of poor adherence. However, it is unlikely that there was poor adherence in the group of patients we studied. This was a short 2-week observational study and all participants provided all the measurements of FeNO and PEF on a twice daily basis. As they had to take their inhaler treatments after taking these measurements, we presumed that this happened as this would be their usual treatment. One potential issue with the portable FeNO machine is its expense, which will preclude its widespread use as a home monitoring device for an individual patient. However, if a 2 -week monitoring period is sufficient to predict future risks of exacerbations and help to prevent these, then the value of the FeNO monitor would be increased.

In conclusion, diurnal variation, as well as day-to-day variation in FeNO, can be used as a surrogate biomarker of asthma control and as a predictor of the risk of future exacerbation. Further prospective studies are needed to clarify which markers could be combined to provide the best prediction for poor asthma control and future risks of exacerbation. Whether the daily and diurnal fluctuation of FeNO could be used to optimise asthma management should also be studied.

\section{Acknowledgements}

We thank Bedfont Scientific Ltd (Rochester, UK) for allowing us to use the portable analyser (NObreath) to record FeNO.

\section{References}

1 Taylor DR, Bateman ED, Boulet LP, et al. A new perspective on concepts of asthma severity and control. Eur Respir J 2008; 32: 545-554.

2 Global Initiative for Asthma. Global strategy for asthma management and prevention (GINA). Available from: www.ginasthma.org Date last updated: December 2012. Date last accessed: September 30, 2013.

3 Zhang J, Yu C, Holgate ST, et al. Variability and lack of predictive ability of asthma end-points in clinical trials. Eur Respir J 2002; 20: 1102-1109.

4 Reddel HK. Peak flow monitoring in clinical practice and clinical asthma trials. Curr Opin Pulm Med 2006; 12: 75-81.

5 Reddel HK, Taylor DR, Bateman ED, et al. An official American Thoracic Society/European Respiratory Society statement: asthma control and exacerbations: standardizing endpoints for clinical asthma trials and clinical practice. Am J Respir Crit Care Med 2009; 180: 59-99.

6 Thamrin C, Nydegger R, Stern G, et al. Associations between fluctuations in lung function and asthma control in two populations with differing asthma severity. Thorax 2011; 66: 1036-1042.

7 Cazzoletti L, Marcon A, Janson C, et al. Asthma control in Europe: a real-world evaluation based on an international population-based study. J Allergy Clin Immunol 2007; 120: 1360-1367.

8 Rabe KF, Adachi M, Lai CK, et al. Worldwide severity and control of asthma in children and adults: the global asthma insights and reality surveys. J Allergy Clin Immunol 2004; 114: 40-47.

9 Peters SP, Jones CA, Haselkorn T, et al. Real-world Evaluation of Asthma Control and Treatment (REACT): findings from a national Web-based survey. J Allergy Clin Immunol 2007; 119: 1454-1461.

10 Bateman ED, Reddel HK, Eriksson G, et al. Overall asthma control: the relationship between current control and future risk. J Allergy Clin Immunol 2010; 125: 600-608.

11 Zeiger RS, Yegin A, Simons FE, et al. Evaluation of the National Heart, Lung, and Blood Institute guidelines impairment domain for classifying asthma control and predicting asthma exacerbations. Ann Allergy Asthma Immunol 2012; 108: 81-87.

12 Bousquet J, Mantzouranis E, Cruz AA, et al. Uniform definition of asthma severity, control, and exacerbations: document presented for the World Health Organization Consultation on Severe Asthma. J Allergy Clin Immunol 2010; 126: 926-938.

13 Accordini S, Corsico AG, Braggion M, et al. The cost of persistent asthma in Europe: an international populationbased study in adults. Int Arch Allergy Immunol 2013; 160: 93-101.

14 Dweik RA, Boggs PB, Erzurum SC, et al. An official ATS clinical practice guideline: interpretation of exhaled nitric oxide levels (FeNO) for clinical applications. Am J Respir Crit Care Med 2011; 184: 602-615.

15 Jones SL, Kittelson J, Cowan JO, et al. The predictive value of exhaled nitric oxide measurements in assessing changes in asthma control. Am J Respir Crit Care Med 2001; 164: 738-743.

16 Michils A, Baldassarre S, Van Muylem A. Exhaled nitric oxide and asthma control: a longitudinal study in unselected patients. Eur Respir J 2008; 31: 539-546.

17 Stern G, de Jongste J, van der Valk R, et al. Fluctuation phenotyping based on daily fraction of exhaled nitric oxide values in asthmatic children. J Allergy Clin Immunol 2011; 128: 293-300.

18 Pijnenburg MW, Floor SE, Hop WC, et al. Daily ambulatory exhaled nitric oxide measurements in asthma. Pediatr Allergy Immunol 2006; 17: 189-193.

19 American Thoracic Society. Proceedings of the ATS workshop on refractory asthma: current understanding, recommendations, and unanswered questions. Am J Respir Crit Care Med 2000; 162: 2341-2351. 
Juniper EF, O’Byrne PM, Guyatt GH, et al. Development and validation of a questionnaire to measure asthma control. Eur Respir J 1999; 14: 902-907.

21 Juniper EF, Guyatt GH, Epstein RS, et al. Evaluation of impairment of health related quality of life in asthma: development of a questionnaire for use in clinical trials. Thorax 1992; 47: 76-83.

22 Miller MR, Hankinson J, Brusasco V, et al. Standardisation of spirometry. Eur Respir J 2005; 26: 319-338.

23 American Thoracic Society, European Respiratory Society. ATS/ERS recommendations for standardized procedures for the online and offline measurement of exhaled lower respiratory nitric oxide and nasal nitric oxide, 2005. Am J Respir Crit Care Med 2005; 171: 912-930.

24 Roberts G, Hurley C, Bush A, et al. Longitudinal study of grass pollen exposure, symptoms, and exhaled nitric oxide in childhood seasonal allergic asthma. Thorax 2004; 59: 752-756.

25 Pijnenburg MW, Bakker EM, Hop WC, et al. Titrating steroids on exhaled nitric oxide in children with asthma: a randomized controlled trial. Am J Respir Crit Care Med 2005; 172: 831-836.

26 Smith AD, Cowan JO, Brassett KP, et al. Exhaled nitric oxide: a predictor of steroid response. Am J Respir Crit Care Med 2005; 172: 453-459.

27 Kharitonov SA, Yates DH, Barnes PJ. Inhaled glucocorticoids decrease nitric oxide in exhaled air of asthmatic patients. Am J Respir Crit Care Med 1996; 153: 454-457.

28 Smith AD, Cowan JO, Brassett KP, et al. Use of exhaled nitric oxide measurements to guide treatment in chronic asthma. N Engl J Med 2005; 352: 2163-2173.

29 de Jongste JC, Carraro S, Hop WC, et al. Daily telemonitoring of exhaled nitric oxide and symptoms in the treatment of childhood asthma. Am J Respir Crit Care Med 2009; 179: 93-97.

30 Szefler SJ, Mitchell H, Sorkness CA, et al. Management of asthma based on exhaled nitric oxide in addition to guideline-based treatment for inner-city adolescents and young adults: a randomised controlled trial. Lancet 2008; 372: 1065-1072.

31 Bodini A, Peroni D, Loiacono A, et al. Exhaled nitric oxide daily evaluation is effective in monitoring exposure to relevant allergens in asthmatic children. Chest 2007; 132: 1520-1525.

32 Volbeda F, Broekema M, Lodewijk ME, et al. Clinical control of asthma associates with measures of airway inflammation. Thorax 2013; 68: 19-24.

33 van der Valk RJ, Baraldi E, Stern G, et al. Daily exhaled nitric oxide measurements and asthma exacerbations in children. Allergy 2012; 67: 265-271.

34 Dennis SM, Sharp SJ, Vickers MR, et al. Regular inhaled salbutamol and asthma control: the TRUST randomised trial. Therapy Working Group of the National Asthma Task Force and the MRC General Practice Research Framework. Lancet 2000; 355: 1675-1679.

35 Thamrin C, Zindel J, Nydegger R, et al. Predicting future risk of asthma exacerbations using individual conditional probabilities. J Allergy Clin Immunol 2011; 127: 1494-1502.

36 Toogood JH, Andreou P, Baskerville J. A methodological assessment of diurnal variability of peak flow as a basis for comparing different inhaled steroid formulations. J Allergy Clin Immunol 1996; 98: 555-562.

37 López-Viña A, del Castillo-Arévalo E. Influence of peak expiratory flow monitoring on an asthma self-management education programme. Respir Med 2000; 94: 760-766.

38 Aggarwal AN, Gupta D, Kumar V, et al. Assessment of diurnal variability of peak expiratory flow in stable asthmatics. J Asthma 2002; 39: 487-491.

39 ten Hacken NH, van der Vaart T, van der Mark TW, et al. Exhaled nitric oxide is higher both at day and night in subjects with nocturnal asthma. Am J Respir Crit Care Med 1998; 158: 902-907.

40 Thamrin C, Taylor DR, Jones SL, et al. Variability of lung function predicts loss of asthma control following withdrawal of inhaled corticosteroid treatment. Thorax 2010; 65: 403-408.

41 Shaw DE, Berry MA, Thomas M, et al. The use of exhaled nitric oxide to guide asthma management: a randomized controlled trial. Am J Respir Crit Care Med 2007; 176: 231-237.

42 McNicholl DM, Stevenson M, McGarvey LP, et al. The utility of fractional exhaled nitric oxide suppression in the identification of nonadherence in difficult asthma. Am J Respir Crit Care Med 2012; 186: 1102-1108. 